\title{
Cartografando teatro e ensino num encontro com a filosofia da diferença
}

\author{
Cartografando teatro y enseñanza en un encuentro con la filosofía de la \\ diferencia
}

\section{Cartographing theater and teaching in a meaning with the philosophy of the difference}

\author{
Caroline Soares de Lima ${ }^{1}$ \\ Dulce Mari da Silva Voss ${ }^{2}$
}

\begin{abstract}
Resumo
Este texto parte da análise realizada numa pesquisa cartográfica em andamento para composição de uma Dissertação de Mestrado Acadêmico em Ensino. Apoiada na Filosofia da Diferença, essa pesquisa leva-nos a pensar o teatro enquanto território de experimentações dos corpos e de produção de subjetividades articulada à criação de perceptos e afectos, razão e emoção como dimensões coexistentes que potencializam a dramatização teatral. O lugar empírico são as oficinas de teatro do Grupo "Os Carlitos", acontecidas em 2018, na cidade de Bagé (RS), cujas experimentações dramáticas foram capturadas pela pesquisadora por meio de fotografias e servem como dispositivos de análise das produções dos corpos e subjetivações. Conclui-se que as experimentações dos atores e atrizes nas oficinas teatrais subvertem a ordem moderna que concebe o teatro como imitação de um mundo real posto, pois se percebe que os movimentos dos corpos intensificam a criação, inventam outras existências, devires.
\end{abstract}

Palavras-Chave: Cartografia; Corpos; Filosofia da Diferença; Subjetividades; Teatro.

\section{Resumen}

Este texto parte del análisis realizado en una investigación cartográfica en marcha para la composición de una Disertación de Maestría Académica en Enseñanza. En la Filosofía de la Diferencia, esta investigación nos lleva a pensar el teatro como territorio de experimentaciones de los cuerpos y de producción de subjetividades articulada a la creación de percepctos y afectos, razón y emoción como dimensiones coexistentes que potencian la dramatización teatral. El lugar empírico son los talleres de teatro del Grupo "Los Carlitos", ocurridos en 2018, en la ciudad de Bagé (RS), cuyas experimentaciones dramáticas fueron capturadas por la investigadora por medio de fotografías y sirven como dispositivos de análisis de las producciones de los cuerpos y subjeciones. Se concluye que las experimentaciones de los actores y actrices en los talleres teatrales subvierten el orden moderno que concibe el teatro como imitación de un mundo real puesto, pues se percibe que los movimientos de los cuerpos intensifican la creación, inventan otras existencias, devires.

Palabras claves: Cartografía; Cuerpos; Filosofía de la Diferencia; subjetividades; Teatro.

\begin{abstract}
This text part of the analysis performed on a cartographic research in progress to composition of a dissertation of Academic Master's Degree in Teaching. Supported in the Philosophy of difference, this research leads us to think of the theater while planning experiments of bodies and for the production of subjectivities articulated to the

\footnotetext{
${ }^{1}$ Especialista em Educação e Diversidade Cultural, Discente do Programa de Mestrado Acadêmico em Ensino da Universidade Federal do Pampa - UNIPAMPA; Bagé, Rio Grande do Sul, Brasil; carol.unipampa@hotmail.com

${ }^{2}$ Doutora em Educação, Docente do Programa de Mestrado Acadêmico em Ensino da Universidade Federal do Pampa - UNIPAMPA; Bagé, Rio Grande do Sul, Brasil; dulce.voss@ gmail.com
} 
creation of Percepts and affections, reason and emotion as coexisting dimensions which potentiate the Theatrical dramatization. The empirical place are the theater workshops of the group "Carlitos", happened in 2018, in the city of Bagé (RS), whose dramatic experiments were captured by the researcher through photographs and serve as devices for analysis of the productions of bodies and subjetivações. It is concluded that the trials of the actors and actresses in theater workshops subvert the modern order that conceives the theater as an imitation of a real world tour, because it realizes that the movements of the bodies intensify the creation, invent other stocks, devires.

Keywords: Cartography; Bodies; Philosophy of the Difference; Subjectivites; Theater.

\section{Introdução}

Este texto surge de uma pesquisa cartográfica em andamento para composição de uma Dissertação de Mestrado acerca de possíveis conexões entre as artes teatrais e o ensino em relação à produção de corpos e subjetividades pelos modos como os sujeitos experimentam a criação dramática. A pesquisa acontece nas oficinas promovidas pelo Grupo de Teatro "Os Carlitos” que ocorrem na Biblioteca Pública Municipal de Bagé (RS). Nelas são feitos jogos teatrais com técnica de voz, corpo, posição de palco, desinibição, improviso, dramatização de músicas e poemas. O grupo se destaca por apresentações de interpretações de obras clássicas, com representações criativas e improvisação de textos, que vão desde monólogos, esquetes e peças teatrais, como "O Auto da Compadecida" de Ariano Suassuna, que foi apresentada em três seções no ano de 2018.

$\mathrm{Na}$ análise das experimentações teatrais opera-se com a cartografia de imagens fotográficas registradas nas oficinas do Grupo de Teatro "Os Carlitos". Levando em conta que, como esclarece Zanella (2013), as imagens são polissêmicas, ou seja, imagens fotográficas são formas de olhar os acontecimentos pelas lentes de quem os capturam, reafirma-se nessa metodologia a intervenção da pesquisadora que não separa sujeito e objeto. Pois, os modos como as imagens são produzidas e analisadas revelam a leitura daquele momento numa perspectiva singular dos acontecimentos. Assim, outro vendo a mesma imagem, cria outras perspectivas.

Nas análises das imagens fotográficas pelas lentes da pesquisadora buscou-se a desterritorialização do "caso" pesquisado, o que acontece quando as narrativas se deslocam do vivido para o narrado, pois, quando se escreve ou se narra algo, já não é o mesmo. A idéia de que narrar um caso envolve também um ethos político que possibilita aproximação, convergências e dissonâncias com outros casos. Outra característica decorrente dessas duas anteriores, refere-se à produção de agenciamentos de enunciação, ou seja:

Mesmo quando vivido, enunciado, protagonizado, emitido por uma singularidade, a narrativa não remete a um sujeito. $\mathrm{O}$ sujeito é ele próprio um agenciamento de 
enunciação, isto é, ele se constitui num plano de consistência por agenciamentos, ele só existe em face de certas engrenagens, de determinados agenciamentos. $\mathrm{O}$ agenciamento de enunciação é, assim, desde sempre coletivo, pois se dá num plano de fluxos heterogêneos e múltiplos que se cruzam incessantemente, possibilitando infinitas montagens. (PASSOS; BARROS In: PASSOS; KASTRUP; ESCÓSSIA, 2015, p.168).

Por isso, na perspectiva da Filosofia da Diferença a criação do pensamento acontece de modo intermezzo, rompe com uma raiz horizontal (original), ele se espalha, se curva, criase linhas de fuga, escapes, não há um único caminho e sim pluri-direções. A cartografia é um mapa sem limites, inventivo, esse roteiro que não se encerra, está em constante expansão. Não é um significado, uma unidade, pois não se pode encaixar pessoas, objetos, pensamentos, arte e ensino, mas cartografar pistas:

Eis, então, o sentido da cartografia: acompanhamento de percursos, implicação em processos de produção, conexão de redes ou rizomas. É assim que Deleuze e Guattari designam sua Introdução: Rizoma. A cartografia surge como um princípio do rizoma que atesta, no pensamento, sua força performática, sua pragmática: princípio inteiramente voltado para uma experimentação ancorada no real (PASSOS; KASTRUP; ESCÓSSIA, 2015, p. 10).

Não há passos da pesquisa e sim uma perspectiva metodológica que produz linhas. Os territórios da pesquisa criam-se na própria experimentação, portanto, no minoritário criam-se relações, germinam processos, sem haver um macro, como acontece em outro tipo de metodologia, por exemplo, em que o pesquisador se afasta da pesquisa.

Ao cartógrafo cabe conhecer e fazer-se no espaço criado, não há um objeto de estudo e/ou um sujeito a priori e sim experimentações que produzem a pesquisa. Não se trata, portanto de apresentar o que está posto, pois não se tem o posto. O método é o caminho que vai sendo traçado, por pessoas, experimentações.

Conhecer não é tão somente representar o objeto ou processar informações acerca de um mundo supostamente já constituído, mas pressupõe implicar-se com o mundo, comprometer-se com a sua produção. Nesse sentido, o conhecimento ou, mais especificamente, o trabalho da pesquisa se faz pelo engajamento daquele que conhece no mundo a ser conhecido. É preciso, então, considerar que o trabalho da cartografia não pode se fazer como sobrevôo conceitual sobre a realidade investigada. Diferentemente, é sempre pelo compartilhamento de um território existencial que sujeito e objeto da pesquisa se relacionam e se codeterninam (ALVAREZ; PASSOS In: PASSOS; KASTRUP; ESCÓSSIA, 2015, p. 131).

Logo, as experimentações vividas pelos sujeitos/personagens desta pesquisa nas oficinas do Grupo "Os Carlitos" tornam-se dispositivos de análise dos processos de subjetivação engendrados e da busca de pistas para traçar conexões entre o teatro e o ensino.

\section{Produção de corporeidades: entre escolas e teatros}


Conforme Foucault (2010), as escolas, as fábricas, os quartéis, as prisões, constituemse historicamente enquanto instituições modernas que operam tecnologias de poder disciplinar para a normalização e docilização dos corpos e das mentes.

Desse modo, a modernidade concebeu as instituições, como lugares de produção de subjetividades disciplinadas, úteis e dóceis, distribuindo os corpos, de forma hierárquica e classificatória nos espaços, exercendo o controle de atividades em relação aos objetos dispostos numa ordem sucessiva de tarefas. Também as funções pedagógicas, administrativas, didáticas nas escolas foram concebidas e agem na produção de governo dos corpos e condutas dos indivíduos:

[...] esses métodos que permitem o controle minucioso das operações do corpo, que realizam a sujeição constante de suas forças e lhes impõe uma relação de docilidadeutilidade, são o que podemos chamar 'disciplinas'. Muitos processos disciplinares existem há muito tempo: nos conventos, nos exércitos, nas oficinas também. Mas as disciplinas se tornaram no decorrer dos séculos XVII e XVIII formulas gerais de dominação. Diferentes da escravidão, pois não fundamentam numa relação de apropriação dos corpos; é até a elegância da disciplina dispensar essa relação custosa e violenta obtendo efeitos de utilidade pelo menos igualmente grandes. (FOUCAULT, 2010, p. 133)

Historicamente, as escolas desempenham a função de seleção e disseminação dos saberes científicos distribuídos numa classificação hierárquica que prima pela instrumentalização dos conhecimentos para formação técnica do contingente de mão-de-obra que disputa espaço no mercado produtivo, o que reforça a necessidade de produção de corpos úteis e dóceis. Nas práticas de governo dos corpos e das condutas que operam o poder disciplinar para produção de uma individualidade disciplinada as técnicas de individuação correspondem: a distribuição dos corpos no espaço, ou seja, cada corpo tem um lugar (a fila); o controle de atividades em relação ao tempo e aos objetos dispostos numa ordem sucessiva de tarefas (o horário fixo das aulas, a organização das turmas, a distribuição das disciplinas, o tempo da prova, etc.); a vigilância hierárquica que se apresenta nas relações de poder na distribuição de funções pedagógicas, administrativas, didáticas e nas sanções normalizadoras que agem sobre as condutas dos indivíduos, medindo capacidades, estabelecendo castigos e gratificações (avaliações, exames).

Percebe-se que muitas escolas permanecem pautando suas ações de ensino desse modo. Em muitas escolas não há lugar para o teatro ou quando há esse se limita a atividades técnicas de encenação e imitação de um real que está posto. Nesse sentido a educação escolar prioriza a cognição para desenvolvimento da inteligência. Como nos diz Bergson (apud ZACHARIAS, 2017) a inteligência prescinde numa automatização de comportamentos, um tipo de controle sobre a nossa existência, como um modo de preservação da vida humana. 
Porém, a inteligência enfraquece os vínculos humanos com a vida e afasta os seres humanos da criação entendida como algo raro, manifestado pela emoção, inserida no plano dos afectos, ou seja, a emoção não é algo provocado por objetos (exemplos: filme, música, poema, uma peça teatral), não é ação que suscita uma reação, não é motivada por sentimentos de alegria ou tristeza, mas é ação criadora que gera o novo (devir): "Criação é aquilo que movimenta a vida, que a coloca em um fluxo constante e a tira de seu estado estático [...] É uma força que impele o ser a movimentar-se" (ZACHARIAS, 2017, p. 31).

Também nas artes teatrais, ao longo dos séculos XVIII a meados do século XX, predominou na Europa um estilo de pensar e fazer teatro pautado na representação dramática de discursos e atos imitativos. Para Lehmann (2007), essa tradição teatral europeia foi conceituada a partir de Brecht como teatro dramático, incluindo, num plano consciente, as categorias imitação e ação, e no plano inconsciente, a tentativa de estabelecer uma função social para o ato teatral, ou seja, por meio de um reconhecimento afetivo, o drama representado estabelece a comunicação entre os atores e a plateia.

O teatro dramático constitui um modo de encenação que limita os movimentos dos corpos à medida que priorizava a imitação, a representação do real como parte do processo artístico, o que inibe a criação. Fazer teatro traduz-se em montagem do drama encenado sob subordinação de um texto que constitui o roteiro das cenas, cenários, elencos e papéis aos atores e atrizes. Embora os personagens dramáticos possam fazer uso de gestos, movimentos e mímicas, o discurso dos atores constituía parte essencial de sua atuação centrada na interpretação do texto. O palco torna-se espelho do mundo real construído ilusoriamente:

[ ] o teatro dramático era construção de ilusão. Ele pretendia erguer um cosmos fictício e fazer que o "palco que significa o mundo" aparecesse como um palco que representa o mundo - abstraindo, mas pressupondo que a fantasia e a sensação dos espectadores participam da ilusão (LEHMANN, 2007, p. 16).

$\mathrm{Na}$ dramaturgia contemporânea surge o teatro pós-dramático, uma arte teatral que reivindica outra forma de fazer teatro para além da imitação via representação de um "real existente". Pautadas na ideia do que não está posto, da criação, as artes teatrais se elevam para além do real. Priorizam o acontecimento e não o sentido, já que buscam encenar e fazer circular diferentes sentidos. Desse modo a dramaturgia contemporânea transforma-se na própria ação de experimentação, o que produz outras corporeidades.

Pensar as conexões entre o ensino e o teatro é o que move essa reflexão. Ver o teatro como força potencializadora do ensino, com suas experimentações do riso, das máscaras, da liberdade criadora e da singularização. Assim, as indagações aparecem: O que o teatro ensina na vida das pessoas? E ele tem algo a ensinar? 


\section{Artes teatrais do Grupo "Os Carlitos"}

As oficinas do Grupo "Os Carlitos” constituem-se nos dispositivos de análise dessas indagações. Experimentações que possibilitam pensar sobre a produção dos corpos e subjetividades como devires. Nesses momentos se misturam corpos, territórios, processos rizomáticos de experimentações das artes que se desterritoralizam constantemente, criações, ímpetos do agora, do novo.

Entrar no campo do devir é estar sempre compondo em nossos corpos algo de inusitado a partir do encontro com o outro, embarcando constantemente em possíveis linhas de fuga desterritorializantes. Entre indivíduos supostamente identificáveis e fechados em si mesmos, o que existe é uma composição de afetos, uma mistura de corpos [...] cada sujeito pode ser definido por uma lista de afetos e devires, quer dizer, ele é, por si só, uma multiplicidade de acontecimentos que nunca cessam de assediá-lo e de gerar efeitos diferenciados em sua vida. (DOREA, 2002, p. 104)

É o que acontece, por exemplo, com os improvisos, que criam momentos singulares, o que se percebe nas cenas capturadas pelas imagens:

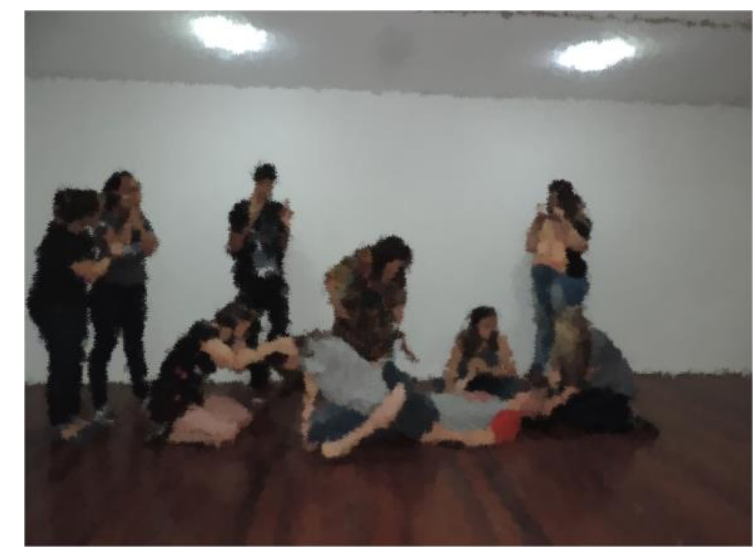

Figura 1 - Imagem da cena o parto

Fonte: Arquivo fotográfico da pesquisadora

A imagem acima se refere ao momento da Oficina Tempos Modernos 1 do Grupo "Os Carlitos" em que alunos criam uma proposta de cena. A cena é composta por atores que estão posicionados em forma de estátua. Enquanto um dos atores vivencia um homem "parindo", outros encenam a parteira, o feto e outros personagens que assistem e registram o parto. Esse momento é o nascimento que está dito, um movimento dos corpos mesmo em representação de estátua, pois, o território foi criado numa improvisação individual para compor um acontecimento em grupo. 


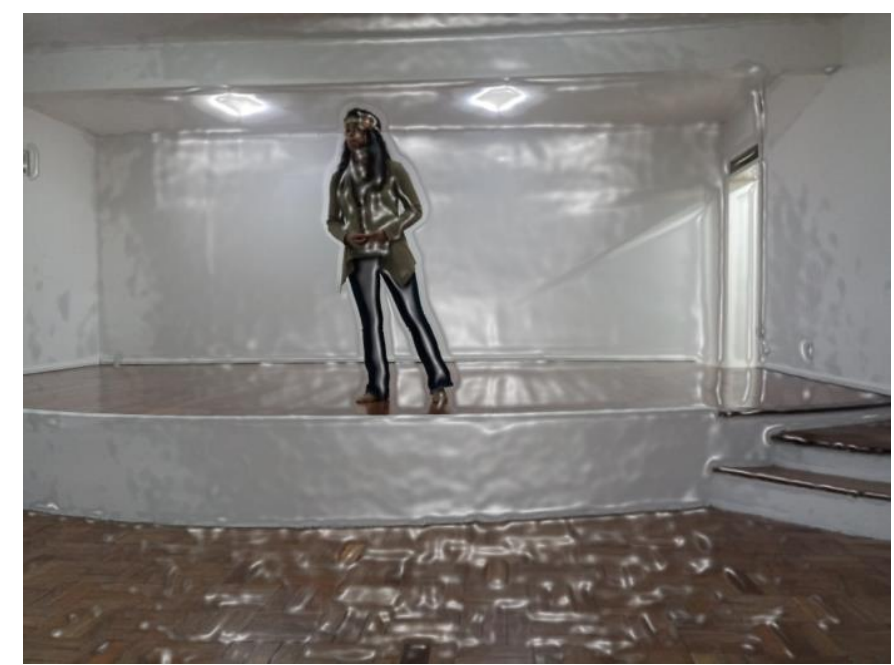

Figura 2 - Imagem da dramatização da música Índios

Fonte: Arquivo fotográfico da pesquisadora

A segunda imagem foi produzida na Oficina Tempos Modernos 2 durante a encenação de uma das atrizes do Grupo ao dramatizar a música Índios (Legião Urbana). A proposta era encenar a letra da música livremente. A atriz criou uma personagem usando de acessórios que remetiam a caracterização de uma indígena, produzindo movimentos que envolviam os que assistiam num processo criativo de sensações e afecções, pois sentiamo-nos todos provocados a viver naquele momento a história por ela interpretada.

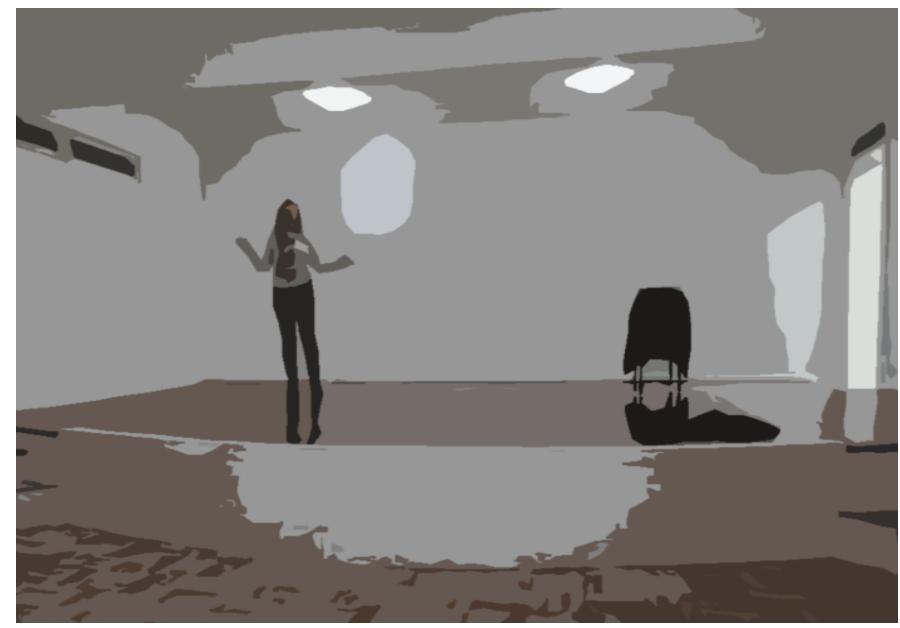

Figura 3: Imagem da dramatização da música Trevo

Fonte: Arquivo fotográfico da pesquisadora

Essa imagem foi capturada também durante a Oficina Tempos Modernos 2, nela a atriz encenou a música Trevo (Anavitória). A proposta era interpretar livremente a letra da música que remete a ideia de um personagem que canta a alguém por ele amado, como dito no trecho: "Tu é trevo de quatro folhas/É manhã de Domingo à toa/Conversa rara e boa/Pedaço de sonho que faz meu querer acordar pra vida". A atriz montou o cenário de um 
ambiente imaginário e surpreendeu pela criação do seu personagem, pois aquele alguém da música a qual se dirigia não era uma pessoa, mas um cão a quem deu nome de Trevo.

As três cenas, aqui trazidas nos levam a refletir sobre a produção de corpos e subjetividades que transitam entre a representação e a criação, como na cena do parto, cujo o nascimento foge do "real" já que não é um ser feminino e sim masculino que pari a criança. Nas outras duas, embora as atuações das atrizes esteja subordinada a um texto, também acontece a criação inusitada de personagens e performances.

Cada criação acontece na singularidade do instante em que atores e atrizes experimentam o teatro de modo singular. Não é o acontecido que importa, mas o acontecer que se cria a partir de um deslocamento, uma desterritorialização do texto, algo não dito, algo novo que produz o movimento dos corpos entre o real e o virtual, compondo as cenas. Como diz Deleuze (2012), os processos de desterritorialização produzem a atualização do real pelo virtual. Nisso reside a potência criadora das artes.

Percebe-se que as experiências vividas nas oficinas possibilitam aos atores e atrizes inventar modos de existência que subvertem a ideia do teatro como representação de mundo inteligível, racional. Afetados pela emoção, esses sujeitos produzem devires: "A emoção criadora surge quando se rompe com o aprisionamento gerado pela inteligência e a percepção se abre para além dos muros da razão" (ZACHARIAS, 2017, p. 31).

Desse modo as artes se tornam criação de afectos e perceptos que intensificam os movimentos dos corpos, permitem entregar-se ao desejo de libertar-se de um mundo préconcebido e acreditar na possibilidade de um novo real, um novo corpo, um outro modo de existência.

É o que acontece, por exemplo, no teatro, com os improvisos, que criam momentos singulares. Assim, como nesses momentos se implicam pessoas, escolhas, territórios, arte, ensino, processos rizomáticos de experimentações das artes que se desterritoralizam constantemente, criações, ímpetos do agora, do novo.

A partir das leituras que me percorrem, entendo que os sujeitos experimentam o teatro não como iguais, nem como sujeitos dados e sim como convergências e dissonâncias entre eus e outros. Percebe-se dessa forma que os acontecimentos e as experiências vividas pelos sujeitos/personagens criam novas singularidades e territórios existenciais.

\section{Aprendendo com "Os Carlitos"}


Pensar possíveis conexões entre o teatro e o ensino na perspectiva da Filosofia da Diferença permite transpor a percepção do vivível e abrir territórios à criação de múltiplas subjetividades e corporeidades. Assim, é possível experimentar aprendizagens e relações onde os corpos se movimentam em ações criadoras de si e com os outros. Trata-se de produzir movimentos que transformam os corpos docilizados, transgredindo a lógica moderna do corpo enquanto organismo biológico e unificado.

Quando Deleuze (2011) cria o conceito corpo sem órgãos, ele redimensiona a condição do corpo unificado, sugerindo uma livre movimentação, a criação de novos agenciamentos, novas invenções, de algo novo, uma experimentação, como linhas de fuga à corporeidade normalizada. As diferentes experimentações corporais colocam em evidência o governo dos corpos. Corpos dóceis estão sob condições de estabelecer relações com a produção, que estabelecem mesmo a "morte" da vontade. Um corpo maquínico trabalha para um fim, estabelece individuações para compor relação de finitude, trata-se, portanto, de um “corpo com órgãos", privado do movimento e programado para produção, para fazer o que lhe é imposto a fazer, sempre como um resultado.

As artes teatrais podem criar corpos sem órgãos, escapando da pura representação/interpretação de personagens ficcionais. A materialidade do corpo do ator não é mais encarnação de um personagem e sim material de dinamização da sua própria forma. $\mathrm{O}$ corpo do ator como criador de imagens se diferencia do corpo como signo que possa ser decifrado, traduzido, interpretado, encenado.

Assim, se diz que o corpo está em liberdade em muitos momentos, não aprisionado eternamente a uma finalidade, pois é criado pelo desejo do movimento uma descontinuidade de sensações, no qual a experimentação é processual.

Nas artes teatrais, a produção de subjetividades é potencializada como multiplicidade de cenas e roteiros que se repetem nos ensaios, mas, a repetição não acontece como cópia do mesmo e sim diferença pura de todas às vezes repetidas.

[...] O ser se diz segundo formas que não rompem a unidade de seu sentido; ele se diz num mesmo sentido através de todas as suas formas - eis por que opusemos às categorias noções de outra natureza. Mas aquilo de que ele se diz difere, aquilo de que ele se diz é a própria diferença. Não é o ser análogo que se distribui nas categorias e reparte um lote fixo aos entes, mas os entes é que se repartem no espaço do ser unívoco aberto por todas as formas (DELEUZE, 2006, p. 284)

As artes da dramaturgia e do ensino podem libertar os corpos de corporeidades estáticas, ao propiciar movimentos e encontros entre corpos que se misturam e se reinventam. Trata-se de fazer pulsar os desejos, transbordar potências, fluxos criadores de devires. O Grupo “Os Carlitos” é um desses territórios abertos à criação de múltiplas corporeidades. 


\section{Referências}

ALVAREZ, J.; PASSOS, E. Cartografar é habitar um território existencial. In: PASSOS, E.; KASTRUP, V.; ESCÓSSIA, L. Pistas do método da cartografia: pesquisa intervenção e produção de subjetividade. Porto Alegre: Sulina, 2015, p. 131-149.

DELEUZE, Gilles. Diferença e repetição. Tradução: Luiz Orlandi e Roberto Machado. São Paulo: Graal, $2^{\mathrm{a}}$ ed., 2006, 350 p.

DELEUZE, G.; GUATARI, F. O Anti- Édipo: capitalismo e esquizofrenia 1, $2^{\mathrm{a}}$ ed. Tradução: Luiz Orlandi. São Paulo: Editora 34, 2011, 557 p.

DELEUZE, G.; GUATARI, F. Mil Platôs: capitalismo e esquizofrenia 2, $2^{\mathrm{a}}$ ed., vol. 04. Tradução: Suely Rolnik. São Paulo: Editora 34, 2012, 200 p.

DOREA, Guga. Gilles Deleuze e Félix Guattari: Heterogênese e Devir. Revista Margem, São Paulo, n. 16, dez. 2002, p. 91-106.

FOUCAULT, Michel. Vigiar e Punir: nascimento da prisão. Tradução: Raquel Ramalhete. Petrópolis - RJ: Vozes, 2010, 296 p.

LEHMANN, Hans-Thies. Teatro pós-dramático. Tradução: Pedro Süssekind. São Paulo: Cosac Naify, 2007. 440 p.

PASSOS, E.; BARROS, R. B. de. A cartografia como método de pesquisa-intervenção. In: PASSOS, E.; KASTRUP, V.; ESCÓSSIA, L. Pistas do método da cartografia: pesquisaintervenção e produção de subjetividade. Porto Alegre: Sulina, 2015, p. 17-31.

PASSOS, E.; KASTRUP, V.; ESCÓSSIA, L. Pistas do método da cartografia: pesquisaintervenção e produção de subjetividade. Porto Alegre: Sulina, 2015, 270 p.

ZACHARIAS, Pamela. (Des) encontros em um lugar qualquer. Tese (Doutorado em Educação). Universidade Federal de Campinas, Faculdade de Educação. Campinas, SP. 2017, $132 \mathrm{p}$.

ZANELLA, Andréa Vieira. Perguntar, registrar, escrever: inquietações metodológicas. Porto Alegre - RS: Sulina, Editora da UFRGS, 2013, 183 p. 